\title{
Willingness of people who are blind to accept autonomous vehicles: An empirical investigation
}

Roger Bennett, Rohini Vijaygopal, Rita Kottasz

Transportation Research Part F: Traffic Psychology and Behaviour

Volume 69, February 2020, Pages 13-27

https://doi.org/10.1016/j.trf.2019.12.012

\section{Abstract}

Attitudes of a sample of $211 \mathrm{UK}$ people who are blind concerning autonomous vehicles (AVs), and the determinants of the willingness of people who are blind to travel in AVs, were examined. Participants answered an open-ended question regarding their attitudes towards level $5 \mathrm{AVs}$ and the results were analysed using a semi-automated structural topic modelling procedure. (Level $5 \mathrm{AVs}$ are fully autonomous anywhere, and do not require controlled areas in which to operate.) Four "topics" emerged from the exercise: (i) "hope" for future independence and freedom to travel offered by AVs to people who are blind, (ii) scepticism that AVs will ever be configured to meet the needs of people who are blind, (iii) concerns over safety, and (iv) the affordability of AVs. The four topics were employed as mediating variables in a structural equation model designed to explain the respondents' willingness to travel in an AV. A number of covariates were presumed to influence the four mediating topics, including a participant's desire for independence, comorbidity, locus of control, and level of generalised anxiety. Three of the mediating variables exerted significant influences on willingness to travel in an AV, i.e., hope for future independence, misgivings about safety, and affordability. Scepticism about AVs did not have a significant effect. Several implications for AV design and for the creation of public information messages promoting $\mathrm{AVs}$ are suggested. In particular, public information campaigns should emphasise the freedom to travel that AVs will provide for people who are blind; reassurances concerning safety; and the inevitability of $A V s$ appearing on the roads of economically developed countries.

\section{Introduction}

This study examines attitudes towards level 5 autonomous vehicles (AVs) held by people who are blind. (Level 5 autonomous vehicles are fully autonomous anywhere, not just in controlled areas [see SAE, 2016].) Grey literature concerning the attitudes of people who are blind towards such vehicles, and their willingness to travel in them, typically assumes that the arrival of AVs will be enthusiastically welcomed (see for example Bohonas et al., 2007, Chapman, 2016, Dearen, 2018, RNIB, 2016, Woyke, 2016). Benefits assumed by this literature include improved abilities to gain paid employment, to attend entertainment and leisure activities, to travel door-to-door without assistance, and to avoid the loneliness that often results from social isolation experienced by people who are blind (O'Day et al., 2004, Bezyak et al., 2017, Claypool et al., 2017). Because people with severe visual impairments cannot drive, they are compelled to rely on taxis, lifts from family and friends, 
and on public transport. Crudden, McDonnell, and Hierholzer (2015) noted the frustrations felt by people who are blind that arise from having to depend on others, in conjunction with fears of possibly having to navigate unfamiliar environments without assistance. As regards the use of public transport, research as well as casual observation confirms that public transport is complex and inconvenient for people with severe visual impairment (Montarzino et al., 2007, Soltani et al., 2011, Bezyak et al., 2017). Buses travel on fixed routes, lifts may be inoperable, bus drivers might fail to announce stops, timetables can be unavailable and/or unreliable (a problematic issue for blind travellers who cannot view transit information [Crudden et al., 2015]). Attitudinal issues among drivers or other passengers could also cause problems.

\subsection{Importance of the issue}

One in five UK residents will experience some form of sight loss during their lifetime (RNIB, 2018). At the time of writing two million UK citizens have some form of sight loss "that is severe enough to have a significant impact on their daily lives, such as not being able to drive" (p.1). The two million includes 360,000 individuals who are registered with the UK's medical authorities as being blind or severely partially sighted. Many more (unregistered) people will have sight problems that prevent them from driving. UK residents who are blind are entitled to financial welfare benefits, which can include a contribution to the cost of travelling. ${ }^{1}$ According to RNIB (2018) estimates, there will be 2.7 million UK residents with a visual impairment by the year 2030 and, due to the rise of diabetes and obesity, this figure will rise to four million by 2050. In the USA, $2.4 \%$ of all 16 to 75 -year olds $(7,675,600$ people) have a visual impairment and around 1.5 million US citizens are "totally blind" (see Footnote 1) (NFB, 2017).

\subsubsection{Policy considerations}

People with severe visual impairments constitute a sizeable proportion of the population. It is essential, therefore, that the voice of this important community be heard in policy debates regarding the introduction of $\mathrm{AVs}$. Vehicle designs should be configured to render AVs accessible to people who are blind (Dearen, 2018, Woyke, 2016) and who, according to Brinkley, Posadas, Sherman, Daily, and Gilbert (2019), need to be involved in the design process ab initio. RNIB (2016) also emphasised the necessity of manufacturers considering the requirements of visually impaired people at an early stage when developing AVs. Manufacturers should not create special models for blind people, $\underline{\text { RNIB }}$ (2016) argued, as special models (or adaption kits) would be expensive to produce and their selling prices could be prohibitive for most blind people. Rather, manufacturers should ensure that their AVs have adequate space for guide dogs and include voice 
control facilities (Hong, 2008) and/or tactile interfaces in Braille (Sucu \& Folmer, 2014). Vehicle designs should provide software-controlled voice-overs that state (i) landmarks along a journey, (ii) which side of a vehicle to exit, and (iii) the presence of obstacles outside an AV (Adnan, Nordin, Bahruddin, \& Ali, 2018). Controls for adjusting air conditioning, changing radio channels, etc., that can be readily operated by people who are blind need to be built into AV designs (Woyke, 2016). Dearen (2018) observed that experimental work in US universities has created software apps to deal with many of these issues that can be downloaded to blind people's smartphones. Technologies also exist to help blind people overcome spatial and navigational problems via voice messages sent to their mobile phones, e.g., identification of specific places and landmarks, entrances to buildings, and nearness of parking facilities (see Bohonas et al., 2007, Brito et al., 2018).

\subsection{Transportation and people who are blind}

The present study considers autonomous vehicles that are fully autonomous anywhere, i.e., level 5 AVs (see SAE, 2016 for information on different levels of autonomy of driverless vehicles). This type of autonomous vehicle, according to Brinkley et al. (2019), has "tremendous mobility potential for individuals who are visually impaired" (p. 1). The advantages of $A V s$ for people who are blind are reported in much of the grey literature on the topic. RNIB (2016), for instance, noted how distance will no longer be an impediment to the ability of people who are blind to travel, thus transforming their lives. Use of AVs should enable people who are blind to participate more fully in society, to reduce social exclusion, to access education and training more easily (Crudden, McDonnall and Hierholzer, 2015), and generally to improve their quality of life (Chapman, 2016, Claypool et al., 2017). Nevertheless, a number of concerns have been voiced regarding the ability of people who are blind to interact with driverless vehicles. Depending on the age at which a person became blind, the individual may not have driven before and might be apprehensive about AVs, especially vis-à-vis their safety (RNIB, 2016). Fears might exist among people who are blind of, for example, a minor system failure (caused perhaps by malicious hacking [cf. Sanbonmatsu, Strayer, Zheng, Biondi, \& Cooper, 2018]) leading to a serious accident (Adnan et al., 2018); of being alone and helpless following a collision (Easton, 2014), of not knowing how to escape from a damaged vehicle (Chapman, 2016), of not being able to contact emergency services following an accident, and of not knowing how to return home from the scene of a collision (Claypool et al., 2017, Halsey, 2017). 


\section{Contribution of the present study}

Although grey literature on the topic suggests that people who are blind will applaud the advent of AVs, little robust research has been undertaken into the views of blind people themselves about driverless vehicles. A study by Brinkley et al. (2019) did investigate the issue by inviting 20 blind people to take a "simulated" test drive in an AV within a laboratory, finding that the simulated test drive helped ameliorate the participants' feelings of distrust of AVs. The simulation also improved the test subjects' beliefs in the usability of $A V s$ and increased their desire to purchase such a vehicle. Apart from this study, the topic is largely unexplored.

This paper presents the results of an empirical study of the attitudes towards AVs and willingness to travel in an autonomous vehicle (AV) within a sample of 211 people who satisfied standard criteria for being blind.? It contributes to contemporary knowledge regarding the attitudes towards $A V s$ of people who are blind, and their willingness to travel in $\mathrm{AVs}$, via the presentation to a sample of people who are blind of a completely openended question concerning their views on driverless vehicles. The participants were not given a list of agree/disagree questions about AVs. Rather, a semi-automated structural topic modelling technique that did not require the construction of a coding scheme was employed to analyse responses. Themes and issues emerged naturally from the procedure, which extended to the completion of regressions to relate the outcomes to the open-ended question to a number of potential explanatory variables. Hence, the study adds to contemporary knowledge about the transportation needs of people who are blind, their willingness to accept new modes of transport, and the governmental policies that will be necessary to introduce people who are blind to driverless vehicles. It presents a novel methodology for determining attitudes towards new transportation technologies and examines in a fresh context the usefulness of a number of variables commonly found to predict attitudes regarding new transportation technologies. Insights provided by the results of the study offer valuable guidance for the direction of future research in the area. The paper proceeds as follows. Firstly, the paper examines general matters to do with transportation issues and people who are blind. The methodology of the investigation is explained, the covariates used in the study are described, and the characteristics of the sample are specified. Results from the structural topic model and from a structural equation model are then given. Finally, the results are discussed and a conclusion, statement of limitations, and suggestions for future research are presented. 


\section{Methodology}

The study proceeded in three stages. Firstly, the participants were asked an open-ended question worded "please tell me (or type a statement if the person was replying electronically) about all the things that come into your mind when you think about driverless vehicles". This was followed by a short questionnaire that examined an individual's characteristics. The use of a single open-ended question at the beginning of a questionnaire has a number of advantages. Responses present a direct view of their thinking, there is no need to devise lists of pre-established questions to explore an issue, and the person is not cued to think and reply in particular ways (Roberts et al., 2014). Study participants were drawn from two sources. The first source comprised beneficiaries of a charity (VoSAP-Specially Able People [www.voiceofsap.com]) that assists disabled people, including individuals who are blind, in India, the USA and the UK; is expanding internationally; and is a research collaborator of the United Nations Committee on the Rights of Persons with Disabilities (UNCRDP). Further participation was secured via a charitable Trust that helps people with disabilities, including people who are blind, in the South East of England. The Trust owns residential accommodation, operates several charity shops and drop-in centres, and has an extensive outreach programme. Two hundred and eleven participants were recruited (81 from VoSap), all of whom were blind (see Footnote 2). One hundred and six members of the sample had some kind of computer software for converting text appearing on a computer screen into speech or onto a Braille printer. These participants answered the open-ended question and the accompanying questionnaire items online. Sixty-six people were questioned by telephone, the remaining 39 face-to-face at premises owned by the two charities. Both charities depend heavily on volunteers who furnish assistance to beneficiaries. Initial contact with potential study participants occurred via these volunteers (who were asked by the management of the relevant charity to request that an individual take part) or directly by telephone calls made by the researchers (who confirmed at the outset that the charity's management endorsed the study). All the beneficiaries of the two charities who were listed as blind were contacted and, given the organisational ratification of the study, acceptance rates were high: $82 \%$ of the people approached by the volunteers and $74 \%$ of those contacted by telephone.

If a person was interviewed by telephone or face-to-face the interviewer either wrote down the reply or recorded the answer on a smartphone. The participant was then asked a series of questions covering the variables listed in the Appendix to the paper. (When questioning the respondents, the ethical principles of the Declaration of Helsinki [WMA, 2013] were followed; consent was obtained from subjects according to the procedure 
suggested by the WMA.) Answers to the open-ended question gathered face-to-face were transcribed and entered as narrative text strings into a Vocab character vector in $\mathrm{R}$ software (Roberts, Stewart, \& Tingley, 2018). Responses procured online were copied and pasted into the vector, each response comprising a row in the file.

Secondly, the responses to the open-ended question were analysed using structural topic modelling (STM) software (Roberts et al., 2014, Roberts et al., 2018). STM is a semiautomated machine-learning qualitative research method that identifies latent structures within responses to an open-ended question. It organises responses into "topics" according to the homogeneity of the participants' comments relating to each topic. A clustering algorithm examines the co-occurrence of words across responses and assigns words to various categories. A certain number of topics (but not their contents) is specified $\mathrm{ab}$ initio and the algorithm computes the probability that a person's response will belong to each topic (e.g., $15 \%$ to topic one; $30 \%$ to topic two, etc.; the percentages summing to 100). "Topic prevalence" figures, i.e., the degrees to which responses belong to various topics, can be aggregated across individuals. The most frequent and important words arising within each topic may be specified and the most representative answers reported. To establish the correct number of topics the model is computed for differing numbers of topics (e.g., two to six) and the best solution (in terms of internal homogeneity and the greatest level of discrimination) is selected (for details see Roberts et al. (2014)). Crucially, topics emerge from the data and are not pre-assumed. There is no requirement for the researcher to construct a coding scheme and hence it is not necessary to predetermine categories and/or dimensions for an analysis or to specify examples to guide the people completing the coding. Human coding can be influenced by a researcher's own theoretical position, background knowledge and reading. Also, human coders may tire and lose concentration. STM discovers topics from data rather than pre-assuming them. The topics that emerge may or may not correspond with a researcher's original expectations. Similarities and differences with extant theories are highlighted.

STM allows the incorporation of covariates into an analysis (a facility not available when using factor analysis or latent Dirichlet clustering). Thus, topic prevalence figures for each participant can be employed as the dependent variable in regressions with covariates (e.g., age, gender and other personal characteristics) as the independent variables. This can indicate the extents to which the selected independent variables influence a participant's specification of topics. Thirdly and finally, a structural equation model (SEM) was constructed containing variables that help explain the participants' willingness to travel in AVs. 


\subsection{The covariates}

In the absence of literature specifically dealing with the topic of the current research, a review of literature regarding acceptance of new transportation opportunities in general (e.g., electric cars) and of other new technologies, was undertaken. This revealed a number of frequently recurring discussions of variables that are potentially relevant for explaining attitudes towards AVs among people with visual impairments (see for example Egbue and Long, 2012, Rezvani et al., 2015, Bansal et al., 2016, Anania et al., 2018, Acheampong and Cugrullo, 2019). The variables in question often involve personal locus of control and propensities to experience feelings of anxiety. Literature in the fields of disability and visual impairment also suggests that the desire for independence is an important motivating factor where transportation is concerned. Research undertaken by the authors in relation to transport and various forms of ambulatory and intellectual disability found that comorbidity and various demographic considerations can affect views regarding new forms of transport among people with disabilities (Bennett and Vijaygopal, 2018, Bennett et al., 2019). Each of these variables is discussed below.

\subsubsection{Desire for independence}

"Dependence" entails "a desire to be taken care of by others or the ability to lean on others for support" (Nagurney, Reich, \& Newsom, 2004 p.215). Independence, conversely, involves the desire to take care of oneself and to stand alone when dealing with problems. Dependence on others may result in lack of initiative (Maneli et al., 2007, Garaigordobil and Bernaras, 2009), and possibly in depression (Maneli et al., 2007: Thurston, 2010). This could be especially severe among individuals who lose their sight after early childhood and then face the task of "internal reorganisation" (Cholden, 1954, p. 207). Transportation availability has been found to be a major determinant of levels of independence among people who are blind, and independence is known to be a primary antecedent of their quality of life (Azenkot et al., 2011). In principle, the availability of AVs should reduce a blind person's dependence on others and enhance the individual's adaptation to blindness (Bow, 2001).

Individuals have differing feelings of innate need for independence (Nagurney et al., 2004, Montarzino et al., 2007, Gignac and Cott, 1998, Pomerantz, 2019). Thus, sentiments regarding $\mathrm{AVs}$, i.e., an innovation that offers a blind person a higher degree of independence, might be more favourable among people who value their independence most dearly. Self-perceptions of the levels of independence held by people who are blind vary among individuals (cf. Wilkin, 1987) and may depend in part on environmental factors (e.g., extent of family support, quality of the person's [physically adapted] 
accommodation), and on people's self-assessments of how much assistance they need (Gignac \& Cott, 1998).

\subsubsection{Locus of control}

People who are blind and who possess a high "locus of control" (Rotter, 1966) have high expectations of their abilities to control events, environments or outcomes (Papadopoulos, Montgomery, \& Chronopoulou, 2013). "Internal" locus of control (LoC) refers to the extent of a person's belief that events and outcomes are determined by effort and ability; "external" LoC involves the perception that outside forces substantially determine outcomes. Several considerations suggest links between LoC and attitudes regarding AVs held by people who are blind, although the results of studies into the matter have been mixed (see Papadopoulos, 2014 for details of relevant literature). LoC is relevant for the present study for three main reason. Firstly, it has been found to predict attitudes and behaviour vis-à-vis travel safety (Özkan and Lajunen, 2005, Huang and Ford, 2012). Secondly, LoC in general is known to affect the travel behaviour of people with disabilities (see, for example, Partridge and Johnstone, 1989, Gruber-Baldini et al., 2009). Thirdly, the construct is relevant in the present context considering its known connections with intention to use AVs (see Payre, Cestac and Delhomme, 2014 for information regarding this matter).

A number of studies of connections between visual impairment and levels of LoC have concluded that high internal LoC helps visually impaired people to adjust psychologically and to adapt their behaviour to meet the challenges of loss of sight (see Papadopoulos, 2014). Papadopoulos (2014) reported significant correlations between being blind and having low internal LoC, concluding that LoC plays a "crucial role" in a person's adjustment to "the daily challenge of living with blindness" (p.671). Stinnette (2009) also found that the higher an individual's internal LoC the better the person adapted to vision loss. Using an AV could be an important part of successful adaptation.

Levels of internal LoC can affect the amount of stress that individuals experience in travel situations (Navaco, Stokols, Campbell, \& Stokols, 1979), and stress that acts as a barrier to participation in everyday life might be felt more acutely by people with disabilities (see Park, Faulkner, \& Schaller, 2003). Individuals with low internal locus of control may fear having to use a fresh and untried means of transport, whereas people with high internal LoC people (who believe that they can exert control over different outcomes of their lives) might welcome the introduction of AVs (cf. Chiteji, 2010). Research has shown, moreover, that individuals high on internal LOC are significantly more likely to be open to innovative ideas, and to be more willing to use new technologies (see McElroy, Hendrickson, Townsend, \& DeMarie, 2007). Such considerations imply that people who 
are blind and have high internal locus of control might possess attitudes towards AVs that are more favourable than those of people with low LoC.

\subsubsection{Generalised anxiety}

Some people experience feelings of deep anxiety more often and more intensely than do others. Gossling (2017) noted how "anxiety permeates the automotive transportation system" given that "the automobile is an unsafe space in itself" (p.68), and since riding in a vehicle exposes a person to risk. Anxiety, according to the American Psychiatric Association is "the apprehensive anticipation of future danger or misfortune accompanied by a feeling of dysphoria or somatic symptoms of tension" (APA, 2000 p.355). It is a distressing condition and is typically accompanied by frustration and stress. Anxiety is not the same as "fear", however, because fear is a direct response to a specific threat whereas anxiety is a longer-term condition (APA, 2000). The term "generalised anxiety" describes the situation that arises when people constantly feel anxious about their lives and about a wide range of situations and issues (NHS, 2018). Generalised anxiety has been found to be especially common among disabled people who become increasingly dependent on others ( $\underline{\text { Christie et al., 2017) }}$, e.g., for transportation ( $\underline{\text { Holland \& Walker, }}$ 2015).

Transportation anxiety can engender feelings of nervousness and discomfort (even dread) about travelling in a vehicle (Butcher, 2018). In extreme cases transportation anxiety can involve dystychiphobia (irrational fear of accidents), amaxophobia (irrational fear of riding in a vehicle), or both. Anxiety relating to transportation is more likely to arise among people

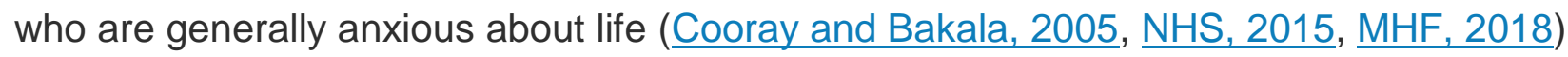
and perhaps about the safety of new technologies. An international survey of 5000 drivers completed by Kyriakidis, Happee, and de Winter (2015) found AV safety to be a major concern of the respondents, particularly among individuals high in "neuroticism". Such considerations imply that people who are blind and who experience high-generalised anxiety may possess less favourable attitudes towards the new technology of AVs.

\subsubsection{Comorbidity}

Although there exists limited data on the extent of comorbidity among people with visual impairment (van Nispen, de Boer, Hoeijmakers, Ringens, \& van Rens, 2009), studies have suggested that various degrees of comorbidity affect the health, mobility and lifestyles of many people who are blind (see Crewe, Jones, \& Kim, 2006). Comingled disabilities affect people's daily lives in disparate ways that may involve stress and anxiety (Bogart, 2014). Thus, the attitudes towards a new and convenient transportation opportunity (such as AVs) of people who are blind and who have compound disabilities may vary. Individuals with 
severe comingled disabilities might be extremely keen to use a novel transportation technology (AVs) that facilitates their capacity to travel independently (Forber-Pratt, Lyew, Mueller and Samples, 2017).

\subsubsection{Controls}

A priori a number of demographic variables may be expected to influence attitudes towards AVs. Age is relevant to the investigation because age can impact on physical activities such as the use of transportation (Topinkova, 2008, DWP, 2018), and older people are more likely to be socially isolated ( $\underline{\mathrm{RNIB}, 2003})$. Gender was included as it is known that females with disabilities, inter alia, can be more vulnerable than males to unemployment and social exclusion (Papworth Trust, 2018). Also, females might have different views to males on the usefulness of new transportation technologies (see Berliner et al., 2018, Sener et al., 2019). Income category was considered since travel can be expensive and may be an inhibiting factor on the transportation choices of low-income people with disabilities (DWP, 2018). A participant's education level was queried because differing education levels could be associated with disparate employment experiences and hence differing transportation needs (ODI, 2015). Ethnicity was considered as individuals from ethnic minorities are overrepresented within the blind community. People of AfroCaribbean heritage are more likely to experience higher levels of glaucoma than other groups; individuals of Asian heritage have a higher probability of developing cataracts, and members of all UK ethnic minority groups are prone to experience lower levels of general health (notably diabetes) than white people, and poor general health impedes the ability to travel. Moreover, according to RNIB (2003), ethnic minority people who are blind tend not to travel "outside the locality where other ethnic minorities live unless they are accompanied by a family member or friend" (p.3). The study also queried the main modes of transport used by the participants and their frequencies of transport.

\subsection{The sample}

Members of the sample had an average age of 39.4 years (range 18 to 71 ). Apart from participants who were blind from birth (16\% of the sample), the sample members had been severely visually impaired for an average of 14.8 years (range four to 44 years). Forty-five per cent of the sample were male; $22 \%$ lived alone, the remainder with a partner and/or with family members. Forty per cent of the participants were in paid employment; mainly in professional, administrative or technical occupations (e.g., computer programmers, teachers, receptionists, telephone sales). Forty per cent of the sample had a post-school educational qualification. Pilot testing revealed a general reluctance of participants to disclose precise details of their personal and household incomes. Hence, people's 
household incomes were queried by asking the participants whether they believed their household income to be higher, lower, or about the same as those of other people (not just blind people). Half the respondents reported a household income lower than others; $18 \%$ stated an income higher than average. These findings broadly match the profile of UK blind people in general (Hewitt and Keil, 2014, RNIB, 2017).

\section{The model}

The model employed in the present study is shown in Fig. 1.

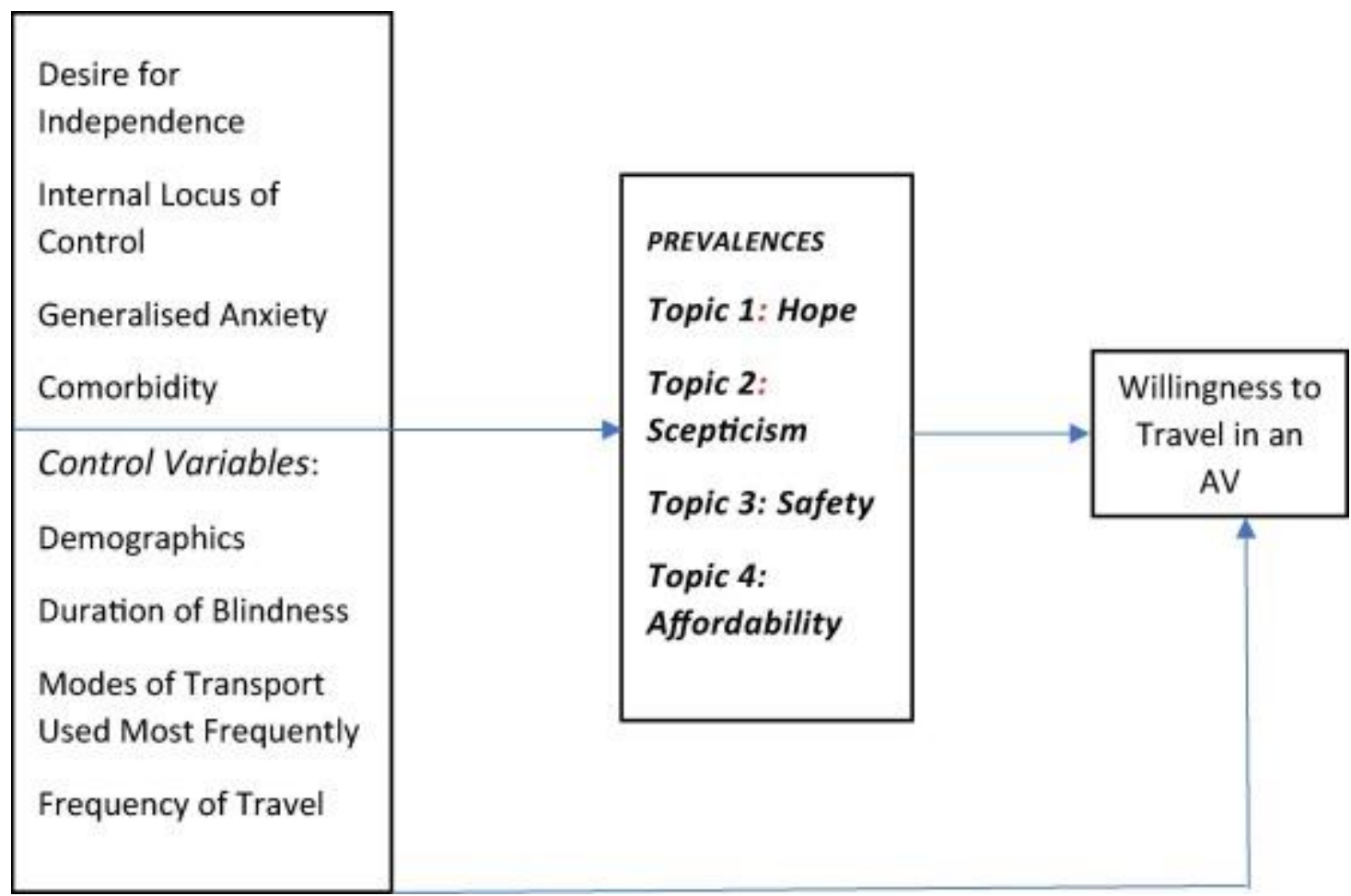

Fig. 1. Structural Model.

\section{Results from the STM}

Table 1 presents the results from the STM. Models for two to seven topics were estimated, a four-topic model producing superior results in terms of exclusivity (i.e., topics containing words with high probabilities of appearing in one topic but low probabilities of appearing elsewhere) and semantic coherence (i.e., responses within a topic containing very similar words). The average length of responses to the request worded "tell me about all the things that come into your mind when you think about driverless vehicles" was 47 words (median 31 words, range ten to 139 words). 
Table 1. All-sample Topic Prevalence Averages.

\section{Topic number and label Prevalence Most common words Representative comment (\%) and phrases*}

1.

\section{$37 \%$}

"Hope" (for the

future of transportation for people who are blind)

2. "Scepticism"

3.

"Safety" concerns

$24 \%$
Will not work, misgivings disbelief, do not trust AVs, unsuitable for people who are blind, suspect they will never happen, unproven technology, can't be introduced

Dangerous, accidents (fear of), entry/exit obstacles, scary, other traffic (and accidents), too frightened to travel, unsafe

High price, travel allowance (state welfare payment) will not cover cost, pricey, too expensive, would need to cut down on other things, not worth the price, beyond the budget of people who are blind

\begin{abstract}
I always dreamt of driving. Thinking about driverless cars, it makes me feel excited and more independent. When I lived in the US, there were places where I had to travel with no public transport and cab service. The only option left out was to walk. I would love to have a car. It gives me an immense pleasure even to think about what I will be able to do in the future
\end{abstract}

We (people who are blind) always lose out on things like this. I'll believe it when it happens, and if it does they won't be made suitable for us. I don't trust these people (state agencies responsible for people who are blind), we get kicked around and end up with the rubbish (transportation methods). I'm sceptical about the entire thing

The idea scares me stiff. Collisions with other (conventional) vehicles will happen all the time - you travel at your peril in one of these things. The software is bound to fail and then what? How can a blind person cope with an accident or if the car just stops working? Suppose the car knocks somebody down, who's to blame and who will be there to sort things out? The $(A V s)$ are a lot too risky for a blind person like me

They cost an arm and a leg, don't they? I would have to sacrifice so many other parts of my life to be able to buy one. It's an extravagance that few blind people could afford and anyway they might not be worthwhile considering how many taxi rides I can get with that amount of money. Even if I bought one it would have to be adapted and l'll bet that adaption kits will be very expensive and certainly not within the (financial) grasp of any (blind) person that I know 
The words and phrases shown are summary interpretations of the many words and phrases used to describe these feelings.

The major topic prevalence related to the "hope" for the greater freedom and independence that the use of an $\mathrm{AV}$ would bring. Responses in this category included statements that "I must start saving up to buy one", "they will liberate our lives" and "how I would love to own one". "I will be able to navigate with pinpoint accuracy, currently I get lost at least once a week," opined one of the respondents. Conversely, the second topic prevalence displayed a considerable degree of scepticism towards $\mathrm{AVs}$, extending to doubts about the feasibility of AVs and to whether they will accommodate the needs of people who are blind. Concerns included the possible unwillingness of manufacturers to modify AVs for people who are blind and of vehicle controls being inappropriate. Topic three involved concerns about the safety of AVs, e.g., of being alone and helpless in the event of an accident, and of not having access to first aid facilities. Topic four contained expressions of concern about the cost of leasing or buying a driverless vehicle and of the government not helping them to meet the cost of leasing or buying a vehicle (see Footnote 1).

\subsection{Analytical procedures}

Response figures for the four topic prevalence variables were employed in a structural equation model (SEM) containing variables intended to explain topic prevalence allocations and designed to relate the topic prevalence allocations to the sample members' willingness to travel in an AV. The model was estimated using the method of partial least squares (PLS), because PLS does not impose any requirements regarding the distributions of independent variables and since the study involved "theory building" rather than "theory testing". Fig. 1 assumes that the covariates affect willingness to travel via the mediating variables, and possibly exert direct effects independently of the mediators.

\subsubsection{Measurement of variables}

Internal locus of control was measured using seven items based on the Pearlin Mastery Scale (Pearlin \& Schooler, 1978), a scale that has been used extensively in healthcare and disability contexts (e.g., Eckland, Erlandsson, \& Hagell, 2012). The scale items assess the degree to which individuals perceive themselves to be in control of forces that significantly affect their lives. "Mastery" has been found to provide a protective buffer for an individual's mental and physical health and well-being when facing persistent life stresses, e.g., severe visual impairment. Responses to the seven items were factor analysed, a onefactor solution emerging (lambda $=5.69$; Cronbach's alpha $=0.89$ ). Tendency to 
experience generalised anxiety was evaluated via Spitzer, Kroenke, and Williams (2006) short-form seven-item "Hopkins Anxiety Proneness Scale", a factor analysis of which produced a single-factor solution explaining $82 \%$ of total variance (alpha $=0.89$ ). Desire for independence was assessed through five items adapted from Nagurney et al. (2004). Four items adapted from Konig and Neumayr (2017) were employed to assess willingness to travel in an AV (lambda $=3.28$, alpha $=0.86$ ). Four items based on ForberPratt et al. (2017) was used to measure perceived intensity of disability (lambda = 3.5, alpha $=0.90)$. Apart from factual queries all items were scored using five-point agree/disagree scales. (Five rather than seven or 10-point scales were employed because the respondents were blind and had to listen to the instructions accompanying the questions or to read them in Braille.)

A questionnaire was constructed (see the Appendix) containing the open-ended question, the above items, and a number of socio-demographic queries. This was discussed with two senior managers in each of the charities collaborating with the investigation and with two senior academics in the disabilities studies domain. This resulted in minor adjustments to the wordings of certain items. The document was then pre-tested face-to-face on seven people in the first of the participating charities, and then via an online distribution to 30 individuals. Nearly all the respondents reported that they relied on lifts from friends and family "all the time" or "very often", and very few used taxis. The only "mode of travel" variable for which there was substantial variation was the degree to which a participant used public transport. Hence this variable was used to reflect "mode of travel" (see the Appendix). The ethnicity measure was based on a simple question as to whether the participant was white or non-white. People blind from birth will have been told this, but are unlikely to want to enter into further and more detailed discussions regarding their ethnicity. A binary variable was formed from the information on ethnicity that was provided. The pre-test of the questionnaire asked participants to place their household incomes into categories ranging, in $£ 6 \mathrm{~K}$ divisions, from $£ 15 \mathrm{~K}$ to $£ 95 \mathrm{~K}$ or above. However, the respondents were often unable or unwilling to give a figure. Also, some people lived in sheltered accommodation where the concept of "household income" has little meaning. Therefore, the sample members were requested to state whether they regarded their household income to be higher than that of most other people; lower; or about the same as that of most other people.

\section{Results from the structural equation model}

$\underline{\text { Table } 2}$ gives the results of the regression analysis. It can be seen from Table 2 that willingness to travel in an AV was influenced positively and significantly by the "hope for 
the future" variable and negatively and significantly by concerns for safety and misgivings about affordability. Significant direct effects on willingness to travel occurred in relation to desire for independence, internal locus of control, generalised anxiety and the presence of comorbidity. (All the variance inflation factors for the variables shown in Fig. 1 had a value less than five, indicating the absence of serious multicollinearity.) As regards the mediating variables, "hope" was affected positively and significantly by desire for independence, locus of control, the presence of comorbidity, extent of use of public transport, and frequency of travel. "Scepticism" was influenced negatively and significantly by locus of control and comorbidity and positively by generalised anxiety. "Safety" concerns were impacted positively and significantly by generalised anxiety and negatively by locus of control. None of the variables in the model had a significant effect on "affordability".

Table 2. Regression Results. Explanatory
variables

\section{Dependent variables}

\begin{tabular}{|c|c|c|c|c|}
\hline ence: & $\begin{array}{l}\text { Topic } 2 \\
\text { Prevalence: } \\
\text { Scepticism }\end{array}$ & $\begin{array}{l}\text { Topic } 3 \\
\text { Prevalence: } \\
\text { Safety }\end{array}$ & $\begin{array}{l}\text { Topic } 4 \\
\text { Prevalence: } \\
\text { Affordability }\end{array}$ & $\begin{array}{l}\text { Willingness } \\
\text { Travel in an } \\
\text { AV }\end{array}$ \\
\hline
\end{tabular}

Topic 1

Prevalence:

Hope

Topic 2

Prevalence:

$-0.11(1.01)$

(0.157)

Scepticism

Topic 3

Prevalence:

Safety

Topic 4

Prevalence:

Affordability

\begin{tabular}{|c|c|c|c|c|c|}
\hline $\begin{array}{l}\text { Desire for } \\
\text { Independence }\end{array}$ & $\begin{array}{l}0.31(2.65)= \\
(0.004)\end{array}$ & $\begin{array}{l}0.07(0.019) \\
(0.492)\end{array}$ & $\begin{array}{l}-0.19(1.44) \\
(0.076)\end{array}$ & $\begin{array}{l}-0.11(1.47) \\
(0.456)\end{array}$ & $\begin{array}{l}0.31(2.99)= \\
(0.001)\end{array}$ \\
\hline $\begin{array}{l}\text { Internal Locus of } \\
\text { Control }\end{array}$ & $\begin{array}{l}0.36(3.95)^{*} \\
(0.000054)\end{array}$ & $\begin{array}{l}-0.27(2.11)_{-}^{*} \\
(0.018)\end{array}$ & $\begin{array}{l}-0.37(3.16)= \\
(0.001)\end{array}$ & $\begin{array}{l}-0.12(0.099) \\
(0.461)\end{array}$ & $\begin{array}{l}0.28(3.00)= \\
(0.001)\end{array}$ \\
\hline $\begin{array}{l}\text { Generalised } \\
\text { Anxiety }\end{array}$ & $\begin{array}{l}0.14(1.48) \\
(0.070)\end{array}$ & $\begin{array}{l}0.29(3.09)= \\
(0.001)\end{array}$ & $\begin{array}{l}0.29(3.07)^{-*} \\
(0.001)\end{array}$ & $\begin{array}{l}0.09(0.101) \\
(0.459)\end{array}$ & $\begin{array}{l}-0.26(2.09)_{-}^{*} \\
(0.012)\end{array}$ \\
\hline
\end{tabular}

$-0.33(3.88)=$

$(0.000071)$

$-0.28(2.69)$

(0.004)

$(0.012)$ 


\begin{tabular}{|c|c|c|c|c|c|}
\hline \multirow{2}{*}{$\begin{array}{l}\text { Explanatory } \\
\text { variables }\end{array}$} & \multicolumn{5}{|c|}{ Dependent variables } \\
\hline & $\begin{array}{l}\text { Topic } 1 \\
\text { Prevalence: } \\
\text { Hope }\end{array}$ & $\begin{array}{l}\text { Topic } 2 \\
\text { Prevalence: } \\
\text { Scepticism }\end{array}$ & $\begin{array}{l}\text { Topic } 3 \\
\text { Prevalence: } \\
\text { Safety }\end{array}$ & $\begin{array}{l}\text { Topic } 4 \\
\text { Prevalence: } \\
\text { Affordability }\end{array}$ & $\begin{array}{l}\text { Willingness to } \\
\text { Travel in an } \\
\text { AV }\end{array}$ \\
\hline Comorbidity & $\begin{array}{l}0.29(2.55)^{*} \\
(0.006)\end{array}$ & $\begin{array}{l}-0.26(2.55)^{*} \\
(0.006)\end{array}$ & $\begin{array}{l}-0.14(0.005) \\
(0.148)\end{array}$ & $\begin{array}{l}0.11(1.00) \\
(0.159)\end{array}$ & $\begin{array}{l}0.24(2.18)_{-}^{*} \\
(0.013)\end{array}$ \\
\hline Age & $\begin{array}{l}-0.17(1.22) \\
(0.112)\end{array}$ & $\begin{array}{l}0.10(1.22) \\
(0.112)\end{array}$ & $\begin{array}{l}0.18(1.08) \\
(0.141)\end{array}$ & $\begin{array}{l}-0.03(0.006) \\
(0.476)\end{array}$ & $\begin{array}{l}0.10(1.10) \\
(0.460)\end{array}$ \\
\hline Gender & $\begin{array}{l}0.06(0.33) \\
(0.371)\end{array}$ & $\begin{array}{l}-0.14(1.16) \\
(0.124)\end{array}$ & $\begin{array}{l}0.90(0.34) \\
(0.367)\end{array}$ & $\begin{array}{l}0.10(0.090) \\
(0.464)\end{array}$ & $\begin{array}{l}0.07(0.060) \\
(0.476)\end{array}$ \\
\hline Income & $\begin{array}{l}0.11(1.11) \\
(0.464)\end{array}$ & $\begin{array}{l}-0.05(0.080) \\
(0.468)\end{array}$ & $\begin{array}{l}0.05(0.080) \\
(0.468)\end{array}$ & $\begin{array}{l}0.06(0.090) \\
(0.464)\end{array}$ & $\begin{array}{l}0.17(1.25) \\
(0.106)\end{array}$ \\
\hline Education & $\begin{array}{l}0.15(1.22) \\
(0.112)\end{array}$ & $\begin{array}{l}-0.10(1.08) \\
(0.141)\end{array}$ & $\begin{array}{l}-0.03(0.061) \\
(0.476)\end{array}$ & $\begin{array}{l}0.14(1.15) \\
(0.126)\end{array}$ & $\begin{array}{l}0.16(1.04) \\
(0.150)\end{array}$ \\
\hline Ethnicity & $\begin{array}{l}0.10(1.11) \\
(0.134)\end{array}$ & $\begin{array}{l}0.15(1.50) \\
(0.068)\end{array}$ & $\begin{array}{l}0.06(0.090) \\
(0.464)\end{array}$ & $\begin{array}{l}0.15(1.44) \\
(0.076)\end{array}$ & $\begin{array}{l}0.09(0.090) \\
(0.464)\end{array}$ \\
\hline $\begin{array}{l}\text { How Long a } \\
\text { Person has Been } \\
\text { Blind }\end{array}$ & $\begin{array}{l}0.19(1.47) \\
(0.071)\end{array}$ & $\begin{array}{l}-0.03(0.080) \\
(0.468)\end{array}$ & $\begin{array}{l}0.16(1.51) \\
(0.066)\end{array}$ & $\begin{array}{l}0.14(1.50) \\
(0.068)\end{array}$ & $\begin{array}{l}0.07(0.090) \\
(0.464)\end{array}$ \\
\hline Mode of Travel & $\begin{array}{l}0.24(2.19)_{-}^{*} \\
(0.015)\end{array}$ & $\begin{array}{l}0.08(1.04) \\
(0.150)\end{array}$ & $\begin{array}{l}0.08(1.10) \\
(0.136)\end{array}$ & $\begin{array}{l}-0.03(0.040) \\
(0.484)\end{array}$ & $\begin{array}{l}0.02(0.040) \\
(0.484)\end{array}$ \\
\hline $\begin{array}{l}\text { Frequency of } \\
\text { Travel }\end{array}$ & $\begin{array}{l}0.25(2.39)^{*} \\
(0.009)\end{array}$ & $\begin{array}{l}0.10(1.10) \\
(0.136)\end{array}$ & $\begin{array}{l}0.09(1.00) \\
(0.159)\end{array}$ & $\begin{array}{l}0.06(0.090) \\
(0.464)\end{array}$ & $\begin{array}{l}0.06(0.080) \\
(0.468)\end{array}$ \\
\hline $\mathrm{R}^{2}$ & 0.40 & 0.30 & 0.27 & 0.13 & 0.45 \\
\hline Adj. $R^{2}$ & 0.36 & 0.26 & 0.23 & 0.08 & 0.40 \\
\hline es and pro & ity levels i & entheses. & & & \\
\hline
\end{tabular}




\section{Discussion}

Demographic variables failed to influence any of the dependent variables, a finding not in accord with the outcomes of some (but not all) prior research which found that lower age, male gender and higher level of education affected positively the perceptions of AVs held by people with (general) disabilities. However the results of studies have been mixed, and

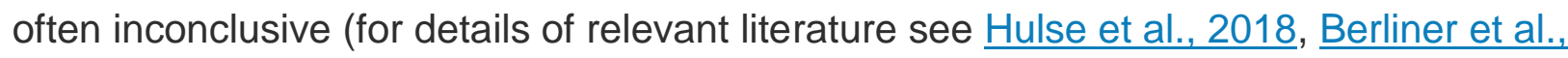
2018, Liljamo et al., 2018, Sanbonmatsu et al., 2018, Sener et al., 2019). A possible reason for the present outcomes is that, for most people (blind or sighted), AVs represent a completely new and untried technology, irrespective of whether a person is young or old, male or female, financially well-off or poor, or whether visual impairment was incurred at birth or in later life. It is clear from Table 2 that three independent variables exerted powerful effects on the mediating topics: comorbidity, locus of control, and generalised anxiety. Additionally, the "hope for the future" mediator depended substantially and significantly on a participant's desire for independence. This last result suggests the desirability of incorporating information about the liberating potential of AVs in public campaigns intended to secure acceptance of AVs among people who are blind. Comorbidity, which is associated with the presence of one or more extra disabilities, will typically mean that an individual requires greater amounts of help with transportation, and will be more dependent on other people and on state and private support services. People with comorbidities often need large amounts of help with daily tasks and, in consequence it seems, were more enthusiastic than others about the liberating aspects of AVs. These individuals were also less sceptical and less concerned about the safety aspects of AVs. The use of public transport might be highly problematic for people with comorbidities. Individuals who are blind and who have other disabilities might experience higher levels of social isolation and possibly may need to travel to health care providers more frequently (see Fried, Ferrucci, Darer, Williamson, \& Anderson, 2004 for a discussion of these issues). AVs may offer a great deal to people who are blind and who have another disability, in terms of greater freedom to travel and general improvements in their quality of life. It follows that public information campaigns directed at people who are blind should include messages aimed specifically at people with comorbidities. The freedom enhancing dimensions of AVs should figure prominently in campaigns.

High internal locus of control influenced all the topics except for affordability, thus confirming the critical role of locus of control in the attitudes and behaviour of people who are blind (cf. Özkan and Lajunen, 2005, Huang and Ford, 2012, Papadopoulos, 2014). Possession of a high internal locus of control indicates a belief in being able to control one's life (i.e., having high self-efficacy vis-à-vis critical activities) and hence to be 
competent to operate a new technology (such as AVs) to one's own advantage and to control a driverless vehicle successfully. Locus of control is likely to affect how a person who is blind will react to information regarding the safety and feasibility of AVs (Srinivasan and Tikoo, 1992, Venkat and Ogden, 2002) and the capacity of AVs to contribute to independent living. High locus of control will normally be associated with favourable responses to such information (and possibly with a desire actively to search for information [Venkat \& Ogden, 2002]). Research has found that individuals with high locus of control tend to be more receptive to positive marketing messages and hence to be easier to influence, provided that they are interested in the product or activity (McCarty and Shrum, 2001). Past studies have found that "self- efficacy expectations" can be manipulated and strengthened within health-related contexts (Smith, 1989, p. 230; see also Chung et al., 2006, Jacobs-Lawson et al., 2011). Accordingly, self-efficacy expectations might be bolstered among people who are blind and who are low in internal locus of control by communicating to them the ease with which a blind person will be able to understand and control AVs, the minimal effort required and the reliability and dependability of AVs. High levels of generalised anxiety had a significantly positive effect on scepticism and safety, and a negative impact on willingness to travel in an AV. Clearly, therefore, public information messages targeted at people who are blind should include messages designed to assuage anxieties and to emphasise the safety features of AVs (cf. Konig \& Neumayr, 2017). Konig and Neumeyr (2017) suggested that AVs should be introduced gradually and with much publicity in order to increase trust and to assuage people's worries about the safety of driverless vehicles. Thus, information campaigns might usefully include scenarios that systematically educate people with high generalised anxiety about the ease of use of AVs and the low risk of accidents that AVs entail. Safety measures could be described (cf. Titov et al., 2013) and various travel scenarios examined in order to build confidence among people who experience generalised anxiety (Gale \& Davidson, 2007).

Scepticism did not significantly predict willingness to travel in an AV, indicating that a person who is blind may be sceptical of the introduction of AVs yet still be favourably inclined towards them. It may be that, in the present context, scepticism matches a general cynicism regarding any new initiative aimed at people who are blind and which involves their welfare. Research completed in the USA has suggested that people who are blind "face special challenges in obtaining care that is safe, effective, timely and patient centred" (O’Day et al., 2004). Similar sentiments have been expressed in the UK vis-à-vis governmental support for people with visual impairments (see RNIB, 2019). Participants who used public transport extensively (the measure of the "mode of transport" variable) 
welcomed the "freedom-enhancing" dimension of $\mathrm{AVs}$, as did people who travelled very frequently.

\section{Conclusion}

Attitudes of the participants towards AVs were characterised by four constructs: hope that AVs will enable people who are blind to travel more freely, extensively, conveniently and independently; scepticism regarding the likelihood that AVs will actually be configured in manners that help people who are blind; and concerns about safety and the affordability of AVs. Participants with high levels of desire for independence welcomed the prospect of travelling in $\mathrm{AVs}$, which were seen to offer exciting opportunities to travel to places not previously accessible to people who are blind. These results were obtained from the unprompted responses of the study participants to an open-ended question. The methodology of the study did not presume any particular patterns of output. Thirty-seven per cent of the present sample directly expressed positive views about AVs, with $45 \%$ being sceptical or holding reservations about safety. This figure of $37 \%$ is comparable to that obtained in a survey completed by Howard and Dai (2014), who reported that $37 \%$ of the respondents were "comfortable" with the idea of AVs. An international survey of 8862 people undertaken by Bazilinskyy, Kyriakidis, and de Winter (2015) concluded that $29 \%$ of the participants could be described as possessing a positive attitude to AVs, with $18 \%$ revealing negative attitudes. Haboucha, Ishaq, and Shiftan (2017) study of 721 US and Israeli drivers found that at least $44 \%$ of the sample had severe hesitations about using an AV. Other surveys have produced similar results (see Bennett et al., 2019). Thus, the outcomes to the present study reinforce the observation of Konig and Neumayr (2017) that for all groups, including people who are blind, "the widespread acceptance and hence adoption of this new technology is far from certain" (p. 42).

The results of the present study have a number of implications both for the manufacturers of $A V s$ and for state policy makers and agencies. Public information campaigns and manufacturers' advertisements will (in the near future) be needed to secure public acceptance of AVs (see Sanbonmatsu et al., 2018), including acceptance by disabled communities (Harper, Hendrickson, Mangones, \& Samaras, 2016). This will require some degree of segmentation of target audiences and of messages. Acheampong \& Cugrullo (2019) observed how public acceptance will depend on approval by "a complex network of heterogeneous potential users who possess different attitudes, perceptions, motivations, preferences, socio-demographic attributes and mobility needs" (p. 350). Government agencies will be tasked with supplying useful and persuasive information about $A V s$ to user communities of people with disabilities alongside the promotional communications of 
manufacturers. Hence, state agencies need to know the sorts of message that will be most effective for persuading people who are blind to accept AVs. The results of the current research provide valuable insights into the use of AVs by people who are blind and offer a template of factors that government agencies should emphasise when formulating public information campaigns aimed at people who are blind and when communicating with them directly in order to secure their acceptance of driverless vehicles. Specifically, the outcomes suggest that communications aimed at people who are blind need to emphasise the freedom and independence that AVs will provide, their safety features, and the fact that AVs are irrefutably the future of road transportation. As regards concerns about affordability, it is relevant to observe that consequent to mass production AVs should be cheap compared to conventional vehicles, due to their simple construction (Alves, 2017). Disability charities have a pivotal role to play in spreading constructive information about AVs to their constituencies.

Furthermore, government policies will be required vis-à-vis AV road and traffic layouts and traffic regulations appropriate for people with disabilities, including people who are blind (Herrmann, Brenner, \& Stradler, 2018). Consideration should be given to special requirements for people who are blind in relation to entrance and exit facilities of $A V s$; internal vehicle control features, user-friendly methods for recharging AV batteries, selfparking systems and vehicle retrieval systems, etc. It is important, therefore, that the representative organisations of people who are blind be involved from the outset in public debates about the future of transportation, and specifically about the creation of policies and regulations (Harper et al., 2016, Lu et al., 2017). State agencies' knowledge of the views concerning AVs of people who are blind will, according to Herrmann et al. (2018), help state agencies to develop and implement appropriate and effective policies on disability-friendly road and traffic layouts and systems. Claypool et al. (2017) argued that "it is imperative that a broader disability community coalesce around a constrained set of policy recommendations" concerning AVs if social inclusion is to be improved in the transportation sphere (p.7).

Governments could encourage early take up of AVs by offering incentives to people who are blind and who are considering leasing or buying a driverless vehicle. In the UK, physically disabled citizens with severe mobility problems qualify for financial mobility allowances with values up to and including the cost of adapting or leasing a new vehicle. At present, UK residents who are blind receive a tax allowance, but since they cannot drive, do not enjoy a separate mobility allowance. Consequent to the introduction of AVs, blind and ambulatory disabled people should in principle have equal access to mobility allowances, although extending allowances to the UK's 360,000 people who are registered blind would be a heavy burden on the government's welfare budget. As an alternative to 
leasing or buying, AVs might become an on-demand shared service for people who are blind (Fragnant \& Kockelman, 2015); with free-floating car sharing or trip sharing door-todoor AV systems wherein a person can summon "Uber-style" a (possibly shared) AV (Anania et. al, 2018 p.220). Charities concerned with visual impairment have an important role to play in lobbying government to make transportation allowances available to people who are blind.

\subsection{Limitations and areas for future research}

The study used a convenience sample of a size constrained by the time and financial resources available for the investigation. However, the researchers did not target participants with any particular characteristics and there is no reason to expect selection bias or overrepresentation of people with particular traits (cf. Etikan, Musa, \& Alkassim, 2016). There are no a-priori grounds for believing that the participants would have wanted to misrepresent their views about AVs and, in the present study, it would not have been appropriate to present the participants with a frame of reference to help them answer the open-ended question. Outcomes to the study provide information on variables considered important as determinants of attitudes towards AVs among people who are blind. This information will be useful for future studies.

An issue with all methodologies based on open-ended interviews is that different respondents may interpret a question in disparate ways, and reply at different lengths and with disparate levels of enthusiasm. Fundamental attitudes might not be revealed. On the other hand, open-ended responses avoid the biased responses that can arise from the cues implicit in structured questioning. In the present study, the authors examined all the responses to identify obvious absurdities, none actually arising. Replications of the investigation in other countries and cultures would be valuable, perhaps using the evidence base provided by the present investigation. Generalised anxiety is a wideranging construct with several dimensions. Examinations of the influences of various aspects of generalised anxiety on the attitudes towards AVs of people who are blind would be worthwhile. Also, the effects of personality traits other than those covered by the present study could usefully be investigated. In addition, the construct of "affordability" deserves further study within the AV and disability context. Affordability might be selfassessed relative to a person's income, to total wealth, to expected future income or wealth, or to the extent that a purchase means having to make sacrifices elsewhere. It is, according to Garner, Stinson, and Shipp (1996), a subjective measure with many facets and psychological manifestations.

Despite these limitations, the study adds substantially and significantly to knowledge concerning the possible responses to the introduction of level $5 \mathrm{AVs}$ of people who are 
blind. So far, developments in the AV domain have focused on the mechanical functions of vehicles, but soon the human aspects of $A V s$ will require attention, including consideration of people with disabilities such as people who are blind. Outcomes to the investigation show a distinct segmentation of attitudes among the present sample of people who are blind, and these results offer a platform for the construction of messages to be directed towards this particular consumer group. Specifically, the outcomes indicate the touch points most likely to encourage people who are blind to want to travel in level $5 \mathrm{AVs}$. Messages based on concepts of freedom, independence, and greater ability to control one's own life should have higher probabilities of influencing people who are blind to accept AVs. Similarly, promotions that emphasise the safety aspects of AVs will seemingly be effective in assuaging the anxieties of potential AV passengers who are blind. Moreover, the results suggest that campaigns segmented simply with respect to demographics are unlikely to succeed.

\section{Appendix. The questionnaire}

\section{General}

How often do you use transportation - daily; 3 or 4 times a week; once a week; once every 2 weeks/3 weeks/four weeks/less than once a month?

What is your location (city or town centre; city or town suburb; rural area)?

How long have you been blind? ( 1 to 3 years; 4 to 6 years; 7 to $9 ; 10$ to 12 ; more than 12 ; "All my life")?

Gender: male/female

Age (17-22; 23-28; 29-34; etc. up to "75 and above")

Income category: Household income regarded as (i) higher than that of most other people, (b) about the same as most other people, (c) lower than that of most other people.

Do you have a post-school qualification (post-graduate; degree/post-school diploma/professional qualification; matriculation qualification; none of the above)?

How do you usually travel (six-point scale: All the time, very often, occasionally, very occasionally, hardly ever, never): I get lifts from family/friends; I get taxis; I use public transport; I walk? 


\section{Comorbidity}

Apart from being blind do you have a physical disability that (five-point scales: $5=$ strongly agree; 1 = not applicable, I do not have a physical disability):

(a) Requires a lot of help to move around inside my house

(b) Requires a lot of help with self-care (dressing, bathing, etc.)

(c) Requires a lot of help with shopping, housework, laundry, etc.

(d) Greatly impedes my ability to travel?

Hopkins Anxiety-proneness Checklist (Measure of Generalised Anxiety)

(a) I often suddenly feel scared for no reason

(b) I often feel fearful

(c) I often feel nervous and shaky inside

(d) I often feel tense or keyed up

(e) I often have spells of panic

(f) I spend a lot of time worrying about things

(g) I often feel afraid that something awful might happen

Pearlin Mastery Scale (Measure of Internal Locus of Control)

(a) There is really no way I can solve some of the problems I have

(b) I often feel that I am being pushed around in life

(c) I have little control over the things that happen to me

(d) I can do just about anything I really set my mind to

(e) I often feel really helpless in dealing with the problems of life

(f) What happens to me in the future mostly depends on me.

(g) There is little I can do to change many of the important things in my life

Desire for Independence

(a) It is very important for me to retain my independence

(b) It is very important for me to work through my problems by myself

(c) I enjoy being taken care of by others (RS)

(d) I would rather have others take care of things for me because it's easier

(e) I don't like having to tackle my problems on my own

Willingness to Travel in an AV

(a) I would be willing to travel in an AV

(b) I would not want to travel in an AV for everyday use, only for special occasions

(c) I would be delighted to travel in an AV

(d) The prospect of travelling in an AV does not appeal to me at all 


\section{References}

Acheampong, R., \& Cugrullo, F. (2019). Capturing the behavioural determinants behind the adoption of autonomous vehicles: Conceptual frameworks and measurement models to predict public transport sharing and ownership trends of self-driving cars. Transportation Research (F): Traffic Psychology and Behaviour, 62, 349-375.

Adnan, N., Nordin, S., Bahruddin, A., \& Ali, M. (2018). How trust can drive forward the user acceptance to the technology? In-vehicle technology forautonomous vehicle. Transportation Research (A): Policy and Practice, 118, 819-836.

Alves, M. (2017). Driven to distraction: Sustainable road safety and the impact of autonomous driving on vulnerable users. Journal of Transport and Health, 74(supplement S4), 587.

Anania, E., Rice, S., Walters, N., Pierce, M., \& Winter, S. (2018). The effects of positive and negative information on consumers' willingness to ride in a driverless vehicle. Transport Policy, 72, 218-224.APA (American Psychiatric Association) (2000), Diagnostic and Statistical Manual of Mental Disorders, Fourth Edition, Washington DC, APA.24R. Bennett et al./Transportation Research Part F 69 (2020) 13-27

Azenkot, S., Prasain, S., Borning, A., Fortuna, E., Ladner, R., \& Wobbrock, J. (2011), Enhancing independence and safety for blind and deaf-blind public transit-riders, Proceedings of the SIGCHI Conference on Human Factors in Computing Systems, Alexandra VA, ACM, pp. 3247-3256.

Bansal, P., Kockelman, K., \& Singh, A. (2016). Assessing public opinions of and interest in new vehicle technologies: An Austin Perspective. Transportation Research (C): Emerging Technologies, 67, 1-14.

Bazilinskyy, P., Kyriakidis, M., \& de Winter, J. (2015). An international crowdsourcing study into people's statements on fully automated driving. Procedia Manufacturing, 3 , 2534-2542.

Bennett, R., \& Vijaygopal, R. (2018). An Assessment of UK Drivers' Attitudes Regarding the Forthcoming Ban on the Sale of Petrol and Diesel Vehicles. Transportation Research Part D: Transport and Environment, 62, 330-344. 
Bennett, R., Vijaygopal, R., \& Kottasz, R. (2019). Attitudes towards Autonomous Vehicles among People with Physical Disabilities. Transportation Research Part A: Policy and Practice, 127, 1-17.

Berliner, R., Hardman, S., \& Tal, G. (2018). Uncovering early adopter's perceptions and purchase intentions of automated vehicles: Insights from early adopters of electric vehicles in California. Transportation Research (F): Traffic Psychology and Behaviour, 60, 712722.

Bezyak, J., Sabella, S., \& Gattis, R. (2017). Public transportation: An investigation of barriers for people with disabilities. Journal of Disability Policy Studies, 28(1), 52-60.

Bogart, K. (2014). The role of disability self-concept in adaptation to congenital or acquired disability. Rehabilitation Psychology, 59(1), 107-115.

Bohonas, S., Lee, A., Malik, A., Thai, C., \& Manduchi, R. (2007), Universal real time navigational assistance: An urban Bluetooth beacon for the blind, Proceedings of the 1st ACM Sigmobile International Workshop on Systems and Networking Support for Healthcare and Assisted Living Environment, New York, ACM, pp. 83-88.

Bow, F. (2001). Accessible transportation. In N. Crewe \& I. Zola (Eds.), Independent living for physically disabled people (pp. 205-209). New York: Jossey-Bass.

Brinkley, Julian, Posadas, Brianna, Sherman, Imani, Daily, Shaundra B., \& Gilbert, Juan E. (2019). An open road evaluation of a self-driving vehicle-human-machine interface designed for visually impaired users. International Journal of Human-Computer Interaction, 35(11), 1018-1032.https://doi.org/10.1080/10447318.2018.1561787.

Brito, D., Viana, T., Sousa, D., Lourenco, A., \& Paiva, S. (2018). A mobile solution to help visually impaired people in public transports and in pedestrian walks. International Journal of Sustainable Development and Planning, 13(2), 281-293.

Butcher, L. (2018), Access to Transport for Disabled People, House of Commons Briefing Paper CBP 601, London, House of Commons.

Chapman, L. (2016), What do self-driving vehicles mean for disabled travellers? Disabled World, 19 December 2016, www.disabled-world.com.

Chiteji, N. (2010). Time preference, noncognitive skills and wellbeing across the life course: Do noncognitive skills encourage healthy behaviour? American Economic Review, 100(2), 200-204. 
Cholden, L. (1954). Some psychiatric problems in the rehabilitation of the blind. Bulletin of the Menninger Clinic, 18(3), 107-117.

Christie, N., Braaf, S., Ameratunga, S., Nunn, A., Jowett, H., \& Gabbe, B. (2017). The role of social networks in supporting the travel needs of people after serious traumatic injury: A nested qualitative study. Journal of Transport and Health, 6, 84-92.

Chung, M., Preveza, E., Papandreau, K., \& Prevezas, N. (2006). Spinal cord injury, posttraumatic stress and locus of control among the elderly. Psychiatry: Interpersonal and Biological Processes, 69(1), 69-80.

Claypool, H., Bin-Nun, A., \& Gerlach, J. (2017).Self-Driving Cars: The Impact on People with Disabilities. Boston: Ruderman.

Cooray, S., \& Bakala, A. (2005). Anxiety disorders in people with learning disabilities. Advances in Psychiatric Treatment, 11(5), 355-361.

Crewe, J., Jones, G., \& Kim, J. (2006). Double jeopardy: The effects of comorbid conditions among older people and vision loss. Journal of Visual Impairment and Blindness, 100, 826-848.

Crudden, A., McDonnell, M., \& Hierholzer, A. (2015). Transportation: An electronic survey of persons who are blind or visually impaired. Journal of Visual Impairment and Blindness, 109, 445-467.

Dearen, J. (2018), Driverless cars give hope to visually impaired, but automakers unsure, CTV News, 13 April 2016, www.ctvnews.ca.DWP (Department of Work and Pensions) (2018), Family Resources Survey 2016/17, London, Department of Work and Pensions, www.gov.uk.org.

Easton, C. (2014), Driverless cars could change lives for disabled people, if we let them, The Conversation, 13 August 2014, Lancaster, Lancaster University, https://theconversation.com.

Eckland, M., Erlandsson, L., \& Hagell, P. (2012). Psychometric properties of a Swedish Version of the Pearlin Mastery Scale in People with Mental IIIness andHealthy People.Nordic Journal of Psychiatry, 66(6), 380-388.

Egbue, O., \& Long, S. (2012). Barriers to widespread adoption of electric vehicles: An analysis of consumer attitudes and perceptions. Energy Policy, 48,717-729. 
Etikan, I., Musa, S., \& Alkassim, R. (2016). Comparison of convenience sampling and purposive sampling. American Journal of Theoretic and Applied Statistics, 5(1), 1-4.

Forber-Pratt, A., Lyew, D., Mueller, C., \& Samples, L. (2017), Disability identity development: A systematic review of the literature, Rehabilitation Psychology, in press website.

Fragnant, D., \& Kockelman, K. (2015). Preparing a nation for autonomous vehicles: Opportunities, barriers and policy recommendations. Transportation Research (A): Policy and Practice, 77, 167-181.

Fried, L., Ferrucci, L., Darer, J., Williamson, J., \& Anderson, G. (2004). Untangling the concepts of disability, frailty, and comorbidity: Implications for improved targeting and care. Journal of Gerontology: Series A, 59(3), 255-263.

Gale, C., \& Davidson, O. (2007). Generalised anxiety disorder. British Medical Journal, $334,579-581$.

Garner, T., Stinson, L., \& Shipp, (1996), Affordability, income adequacy, and subjective assessments of economic well-being: Preliminary findings, Proceedings of the 1996 ACR Conference, Tucson Arizona, Association for Consumer Research, pp. 1-34.

Garaigordobil, M., \& Bernaras, E. (2009). Self-concept, self-esteem, personality traits and psychopathalogical symptoms in adolescents with and without visual impairment. Spanish Journal of Psychology, 12 91), 149-160.

Gignac, M., \& Cott, C. (1998). A conceptual model of independence and dependence for adults with chronic physical illness and disability. Social Science Medicine, 47(6), 739753.

Gossling, S. (2017). Feelings. Amsterdam, Elsevier: Emotions and the Car.

Gruber-Baldini, A., Jian, Y., Anderson, K., \& Shulman, L. (2009). Effects of optimism / pessimism and locus of control on disability and quality of life in Parkinson's disease. Parkinsonism \& Related Disorders, 15(9), 665-669.

Haboucha, C., Ishaq, R., \& Shiftan, Y. (2017). User preferences regarding autonomous vehicles. Transportation Research (C): Emerging Technologies, 78, 37-49.

Halsey, A. (2017), Driverless cars promise far greater mobility for the elderly and people with disabilities, Washington Post, 23 November 2017, www.washingtonpost.com. 
Harper, C., Hendrickson, C., Mangones, S., \& Samaras, C. (2016). Estimating potential increases in travel with autonomous vehicles for the non-driving, elderly and people with travel-restrictive medical conditions. Transportation Research (C): Emerging Technologies, 72, 1-9.

Herrmann, A., Brenner, W., \& Stradler, R. (2018), Autonomous Driving: How the Driverless Revolution Will Change the World, Bradford, Emerald.

Hewitt, R., \& Keil, S. (2014).Investigation of Data Relating to Blind and Partially Sighted People in the Quarterly Labour Force Survey. London: Royal National Institute for the Blind.

Holland, C., \& Walker, I. (2015). The role of transport in the health of older people. Journal of Transport and Health, 2(1), 1-4.

Hong, D. (2008), Development of semi-autonomous vehicle operable by the visually impaired, Proceedings of the IEE International Conference on Multi-sensor Fusion and Integration for Intelligent Systems, Seoul, South Korea, IEE, pp. 539-544.

Howard, D., \& Dai, D. (2014), Public perceptions of self-driving cars: The case of Berkeley, California, Proceedings of the 93rd Annual Meeting of the Transport Research Board, Berkeley CA, University of Berkeley, www.ocf.berkeley.edu.

Huang, J., \& Ford, J. (2012). Driving locus of control and driving behaviours: Inducing change through driver training. Transportation Research (F): Traffic Psychology and Behaviour, 15(3), 358-368.

Hulse, L., Xie, H., \& Galea, E. (2018). Perceptions of autonomous vehicles: Relationships with road users, risk, gender and age. Safety Science, 102, 1-13.

Jacobs-Lawson, J., Waddell, E., \& Webb, A. (2011). Predictors of health locus of control. Current Psychology, 30, 173-183.

Konig, M., \& Neumayr, L. (2017). Users' resistance towards radical innovations: The case of the self-driving car. Transportation Research (F): Traffic Psychology and Behaviour, 44, $42-52$.

Kyriakidis, M., Happee, R., \& de Winter, J. (2015). Public opinion on automated driving: Results of an international questionnaire among 5000 respondents. Transportation Research (F): Traffic Psychology and Behaviour, 32, 127-140. 
Liljamo, T., Liimatainen, H., \& Pollanen, M. (2018). Attitudes and concerns on automated vehicles. Transportation Research (F): Traffic Psychology and Behaviour, 59, 24-44.

Lu, Z., Du., R., Dunham-Jones, E., Park, H., \& Crittendon, J. (2017), Data-enabled public preferences inform integration of $\mathrm{AVs}$ with transport-oriented development in Atlanta, Cities, 63, 118-127.

McCarty, J., \& Shrum, L. (2001). The influence of individualism, collectivism, and locus of control on environmental beliefs and behaviour. Journal of Public Policy and Marketing, 20(1), 93-104.

McElroy, J., Hendrickson, A., Townsend, A., \& DeMarie, S. (2007). Dispositional factors in internet use: Personality versus cognitive style. MIS Quarterly, 31(4), 809-820.

Maneli, M., Sacu, S., Benesch, T., \& Wedrich, A. (2007). Mental health measures of anxiety and depression in patients with retinal detachment. Clinical Practice and Epidemiology in Mental Health, 3(10), 1-12.MHF (Mental Health Foundation) (2018), Learning Disabilities, London, MHF, www.mentalhealth.org.uk.

Montarzino, A., Robertson, B., Aspinal, P., Findlay, C., Hine, J., \& Dhillon, B. (2007). The impact of mobility and public transport on the independence of visually impaired people. Visual Impairment Research, 9(2/3), 67-82.

Nagurney, A., Reich, J., \& Newsom, J. (2004). Gender moderates the effects of independence and dependence desires during the social support process. Psychology and Aging, 19(1), 215-218.

Navaco, R., Stokols, D., Campbell, J., \& Stokols, J. (1979). Transportation stress and community psychology. American Journal of Community Psychology, 7(4), 361-380.

NFB (National Federation of the Blind) (2017), Blindness Statistics, Baltimore Maryland, NFB.NHS (National Health Service) (2015), What is Learning Disability? London, NHS, www.nhs.uk/livewell.

NHS (National Health Service) (2018), Blindness and Vision Loss, London, National Health Service.

O'Day, B., Killeen, M., \& Lezzoni, L. (2004). Improving health care experiences of persons who are blind or have low vision: Suggestions from focus groups. American Journal of Medical Quality, 19(5), 193-200. 
ODI (Office for Disability Issues) (2015), Life Opportunities Survey 2015, London, Department of Work and Pensions, www.gov.uk.org.

Özkan, T., \& Lajunen, T. (2005). Multidimensional traffic locus of control Scale (T-LOC): Factor structure and relationship to risky driving. Personality and Individual Differences, 38(3), 533-545.

Papadopoulos, K. (2014). The impact of individual characteristics on self-esteem and locus of control in young adults with visual impairments. Research in Developmental Disabilities, 35(3), 671-675.

Papadopoulos, K., Montgomery, A., \& Chronopoulou, E. (2013). The impact of visual impairments on self-esteem and locus of control. Research in Developmental Disabilities, 34(12), 4565-4570.

Papworth Trust (2018).Disability in the United Kingdom: Facts and Figures. Papworth Trust: Brentwood MDX.

Park, J., Faulkner, J., \& Schaller, M. (2003). Evolving disease avoiding processes and contemporary anti-social behaviour: Prejudicial attitudes and avoidance of people with physical disabilities. Journal of Nonverbal Behaviour, 27(2), 65-87.

Partridge, C., \& Johnstone, M. (1989). Perceived control of recovery from physical disability: Measurement and prediction. British Journal of Clinical Psychology, 28(1), 5359.

Payre, W., Cestac, J., \& Delhomme, P. (2014). Intention to use a fully automated car: Attitudes and a-priori acceptability. Transportation Research (F): Traffic Psychology and Behaviour, 27, 252-263.

Pearlin, L., \& Schooler, C. (1978). The structure of coping.Journal of Health and Social Behaviour, 19, 2-21.

Pomerantz, M. (2019).Some Thoughts on Independence and Blindness. ACB: Alexandra VA. Rezvani, Z., Jansson, J., \& Bodin, J. (2015). Advances in consumer vehicle adoption research: a review and research agenda. Transportation Research D: Transport and Environment, 34, 122-136.

RNIB (Royal National Institute for the Blind) (2003), Common Barriers to Service Delivery Experienced by People with Sight Problems from Ethnic Minority Backgrounds, London, RNIB,www.lowvision.org.uk/Publications. 
RNIB (Royal National Institute for the Blind) (2016), Are Driverless Cars the Future of Transport for Blind People? London, RNIB.

RNIB (Royal National Institute for the Blind) (2017), Employment and Sight Loss, London, RNIB.

RNIB (Royal National Institute for the Blind) (2018), Key Information and Statistics on Sight Loss in the UK, London, RNIB.

RNIB (Royal National Institute for the Blind) (2019), Government Support, London, RNIB.

Roberts, M., Stewart, B., \& Tingley, D. (2018), STM: An R Package for the Structural Topic Model. (Free software for STM estimation.) www.structuraltopicmodel.com.

Roberts, M., Stewart, B., Tingley, D., Lucas, C., Leder-Luis, J., Gadarian, S., ... Rand, D. (2014). Structural topic models for open ended survey responses. American Journal of Political Science, 58(4), 1064-1082.

Rotter, J. (1966). Generalized expectancies for internal versus external control of reinforcement. Psychological Monographs: General and Applied, 80(1), 1-28.

SAE (Society of Automotive Engineers) (2016), Taxonomy and Definitions Related to Driving Automated Systems for On-Road Motor Vehicles, Washington DC, SAE.

Sanbonmatsu, D., Strayer, D., Zheng, Y., Biondi, F., \& Cooper, J. (2018). Cognitive underpinnings of beliefs and confidence in beliefs about fully automated vehicles. Transportation Research (F): Traffic Psychology and Behaviour, 55, 114-122.

Sener, I., Zmud, J., \& Williams, T. (2019). Measures of baseline intent to use automated vehicles: A study of Texas Cities. Transportation Research (F): Traffic Psychology and Behaviour, 62, 66-77.

Smith, R. (1989). Effects of coping skills training on generalised self-efficacy and locus of control. Journal of Personality and Social Psychology, 56(2), 228-233.

Soltani, S., Sham, M., Awang, M., \& Yaman, R. (2011). Accessibility for disabled in public transportation terminal. Procedia: Social and Behavioural Sciences, 35, 89-96.

Spitzer, R., Kroenke, K., \& Williams, J. (2006). A brief measure for assessing generalised anxiety syndrome: The GAD 7.Archives of Internal Medicine, 166(10),1092-1097. 
Srinivasan, N. and Tikoo, S. (1992), "Effect of locus of control on information search behaviour, in Advances in Consumer Research, Volume 19, eds. John F.Sherry, Jr. and Brian Sternthal, Provo, UT: Association for Consumer Research, 498-504.

Stinnette, D. (2009), Locus of Control and Adjustment to Vision Loss among People with Age-related Macular Degeneration, Walden Dissertations and Doctoral Studies, Ann Arbor MI, Walden University.

Sucu, B., \& Folmer, E. (2014), The blind driver challenge: Steering using haptic cues, Proceedings of the 16th International ACM Conference on Computers and Accessibility, Rochester NY, ACM Press (pp. 3-10).

Titov, N., Dear, B., Johnston, L., Lorian, C., Zou, J., \& Wootton, B. (2013). Improving adherence and clinical outcomes in self-guided internet treatment for anxiety and depression: Randomised controlled trial. PLoS One, 8(7) e62873.

Topinkova, E. (2008). Aging, disability and frailty. Annals of Nutrition and Metabolism, 52, $6-11.26$

Thurston, M. (2010). An enquiry into the emotional impact of sight loss and the counselling experiences and needs of blind and partially sighted people. Counselling and Psychotherapy Research, 10(1), 3-12.

van Nispen, Ruth MA, de Boer, Michiel R, Hoeijmakers, Janneke GJ, Ringens, Peter J, van Rens, Ger HMB (2009). Co-morbidity and visual acuity are risk factors for healthrelated quality of life decline: Five-month follow-up EQ-5D data of visually impaired older patients. Health Qual Life Outcomes, 7(1).https://doi.org/10.1186/1477-7525-7-18.

Venkat, R., \& Ogden, H. (2002). Advertising-induced social comparison and body-image satisfaction: The moderating role of gender, self-esteem and locus of control. Journal of Consumer Satisfaction, Dissatisfaction and Complaining Behaviour, 15, 51-67.

WHO (World Health Organisation) (2015), Change the Definition of Blindness, Geneva, Switzerland, WHO.

WMA (World Medical Association) (2013), Declaration of Helsinki: Ethical Principles for Medical Research Involving Human Subjects, Ferney-Voltaire, France, WMA.

Wilkin, D. (1987). Conceptual problems in dependency research. Social Science Medicine, 24(10), 857-873. 
Woyke, E. (2016), The blind community has high hopes for self-driving cars, MIT Review, 12 October 2016,www.technologyreview.com. 